\title{
Immunopathogenesis and therapy of cutaneous T cell lymphoma
}

\author{
Ellen J. Kim, Stephen Hess, Stephen K. Richardson, Sara Newton, \\ Louise C. Showe, Bernice M. Benoit, Ravi Ubriani, Carmela C. Vittorio, \\ Jacqueline M. Junkins-Hopkins, Maria Wysocka, and Alain H. Rook
}

Department of Dermatology, University of Pennsylvania School of Medicine and the Wistar Institute, Philadelphia, Pennsylvania, USA.

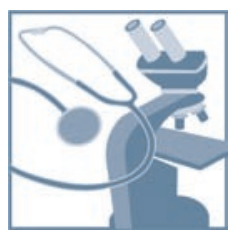

Cutaneous T cell lymphomas (CTCLs) are a heterogenous group of lymphoproliferative disorders caused by clonally derived, skin-invasive $T$ cells. Mycosis fungoides (MF) and Sézary syndrome (SS) are the most common types of CTCLs and are characterized by malignant CD4 ${ }^{+} / \mathrm{CLA}^{+} / \mathrm{CCR} 4^{+}$ $T$ cells that also lack the usual $T$ cell surface markers CD7 and/or CD26. As MF/SS advances, the clonal dominance of the malignant cells results in the expression of predominantly Th2 cytokines, progressive immune dysregulation in patients, and further tumor cell growth. This review summarizes recent insights into the pathogenesis and immunobiology of MF/SS and how these have shaped current therapeutic approaches, in particular the growing emphasis on enhancement of host antitumor immune responses as the key to successful therapy.

Historical perspective. Cutaneous T cell lymphomas (CTCLs) have a wide variety of clinical and histopathological manifestations but are all characterized as extranodal non-Hodgkin lymphomas of malignant, mature $\mathrm{T}$ lymphocytes that target and persist in the skin $(1,2)$. Recently the WHO-EORTC (WHO-European Organization for Research and Treatment of Cancer) jointly issued a new classification of the primary cutaneous lymphomas, and the variety of CTCLs are shown in WHO-EORTC classification of cutaneous $T$ cell and NK/T cell lymphomas (3). Mycosis fungoides $(\mathrm{MF})$ is the most common and best studied of the CTCLs. The term mycosis fungoides originally referred to the mushroomlike nodules seen in the tumor stage of disease (4). MF accounts for approximately $1 \%$ of all non-Hodgkin lymphomas, with a median age of presentation of 57 years and a male/female ratio of $2: 1(5)$. Its incidence is estimated at $0.36-0.90$ per 100,000 person-years $(6,7)$. This rate appears to be stable, although cases of non-Hodgkin lymphoma overall appear to have doubled in the past 2 decades and likely MF/SS is underreported due to nomenclature variances (8).

As shown in Figure 1, patients with classical MF, as originally described by Alibert and Bazin 2 centuries ago, have pink or erythematous scaly patches and plaques that typically appear on sun-protected areas of the skin, such as the proximal extremities, trunk, and buttocks, and have variable degrees of scaling and pruritus (2). It has since been noted that MF actually has protean clinical and histopathological presentations and many variants (see $M F$ variants).

Nonstandard abbreviations used: ATLL, adult T cell leukemia/lymphoma; CCL17, CC-chemokine ligand 17; CCR4, CC-chemokine receptor 4; CLA, cutaneous lymphocyte antigen; CpG-ODN, CpG oligodeoxynucleotide; CTCL, cutaneous T cell lymphoma; CTLA-4, cytotoxic T lymphocyte antigen 4; CXCR3, CXC-chemokine receptor 3; ECP, extracorporeal photopheresis; HDAC, histone deacetylase; HTLV, human T cell lymphotrophic virus; ISCL, International Society for Cutaneous Lymphomas; MF, mycosis fungoides; PUVA, psoralen plus ultraviolet A phototherapy; RAR, retinoic acid receptor; SS, Sézary syndrome; TLR, Toll-like receptor; TNMB, tumor-node-metastasis-blood.

Conflict of interest: The authors have declared that no conflict of interest exists.

Citation for this article: J. Clin. Invest. 115:798-812 (2005).

doi:10.1172/JCI200524826.
MF can mimic benign skin conditions such as chronic eczema, allergic contact dermatitis, or psoriasis, and it is not unusual for the diagnosis to remain elusive for years. It is typically an indolent disorder, but the disease may progress toward or present de novo in more advanced forms, such as with tumors, erythroderma (> 80\% body surface area involved with patches/plaques but without overt leukemic involvement), and blood or organ involvement, accompanied by an increase in morbidity and mortality (See Table 1 for MF lesion definitions). Sézary syndrome (SS) is the leukemic form of the disease in which erythroderma is accompanied by measurable blood involvement by malignant lymphocytes with hyperconvoluted, cerebriform nuclei known as Sézary cells.

The diagnosis of MF/SS is dependent on confirmatory tissue biopsy showing atypical, skin-homing (epidermotropic), malignant $\mathrm{CD}^{+}$lymphocytes, especially those clustering around Langerhans cells in the epidermis, forming the hallmark Pautrier microabcesses on routine histopathology (Figure 2). In MF plaques and tumors, the ratio of $\mathrm{CD}^{+}$to $\mathrm{CD}^{+} \mathrm{T}$ lymphocytes in the skin can also become elevated (>4:1). The malignant $\mathrm{CD} 4^{+} \mathrm{T}$ lymphocytes also frequently lack expression of certain $\mathrm{T}$ cell surface markers, such as CD7 and CD26 $(9,10)$. However, early disease in particular may not show these fully developed histopathological findings and, thus, accurate diagnosis frequently requires biopsies from multiple sites over time. Overt blood involvement has traditionally been measured by examination of a peripheral blood buffy coat smear for hyperconvoluted, cerebriform malignant lymphocytes. Known as the Sézary cell count, the quantification of malignant cells by this method is time consuming and has significant interobserver variability. Recently it has been supplanted by newer, more specific, and more sensitive flow cytometric and molecular techniques (see "The origins of the malignant T cell," below).

MF/SS has a tumor-node-metastasis-blood (TNMB) classification and staging system, originally developed during a 1978 National Cancer Institute Workshop (see TNMB classification for $M F$ and SS and Table 2), with recently proposed modifications by the International Society for Cutaneous Lymphomas (ISCL) (11). Staging evaluation of MF/SS patients typically involves comprehensive skin and physical examination; complete blood count 


\title{
WHO-EORTC classification of cutaneous T cell and NK/T cell lymphomas
}

\author{
MF and variants/subtypes \\ SS
}

Primary cutaneous $\mathrm{CD} 30^{+}$lymphoproliferative disorders

Subcutaneous panniculitis-like T cell lymphoma

Extranodal NK/T cell lymphoma, nasal type

ATLL

Primary cutaneous peripheral T cell lymphoma, unspecified

Aggressive epidermotropic $\mathrm{CD}^{+} \mathrm{T}$ cell lymphoma

Cutaneous $\gamma \delta$ T cell lymphoma

Primary cutaneous $\mathrm{CD}^{+}$small/medium-sized pleomorphic T cell lymphoma

Peripheral T cell lymphoma, other

Adapted with permission from Blood (3).

and quantification of atypical circulating $\mathrm{T}$ lymphocytes; comprehensive metabolic panel; lactate dehydrogenase level; and, in the case of significant clinical lymphadenopathy $(>1.5 \mathrm{~cm})$ or $\mathrm{T} 3 / \mathrm{T} 4$ disease, chest, abdomen, and pelvic computed tomography (CT) scan with contrast and/or whole body positron emission tomography (PET) scanning.

Several studies have demonstated that early MF is typically indolent, and patients with limited patches or plaques who have received skin-directed treatment have median survival similar to that of matched control populations (Table 3). Survival decreases at more advanced stages, and $10 \%$ of all patients will progress to more advanced disease (12). SS patients traditionally have had a poor prognosis, with only approximately $30 \%$ of patients surviving beyond 5 years after diagnosis (13). Important clinical prognostic indicators in MF/SS are $\mathrm{T}$ classification, clinical stage, presence of extracutaneous disease, and patient age. An elevated Sézary count, elevated lactate dehydrogenase level, and peripheral eosinophilia also portend poorer prognosis. Histopathological features that are indicative of a poor prognosis include the presence of significant numbers of large, atypical $\mathrm{CD} 0^{+}$cells suggestive of large cell transformation of the tumor and certain variants (follicular MF, granulomatous) whereas the presence of $\mathrm{CD}^{+}$tumor-infiltrating lymphocytes indicates a more favorable prognosis.

In the past, there were no curative therapies for MF, and the goals of treatment were symptom relief and cosmetic improvement, as early aggressive systemic chemotherapy has not resulted in improved overall survival. The recent trend toward the use of systemic immune-modifying therapeutics appears to be beneficially altering the long-term prognosis of most patients (see "Current and emerging therapies for MF," below). With the exception of human $T$ cell lymphotrophic virus (HTLV) - associated adult T cell leukemia/lymphoma (ATLL), the etiology of the vast majority of CTCLs remains unknown, although various viral and environmental agents have been studied (14).

Recent molecular biology and immunology studies have led to remarkable insights into the origin and function of the malignant $T$ cell, the abnormalities in cytokine expression when tumor burden increases, the immune suppression that characterizes advanced $\mathrm{MF} / \mathrm{SS}$, and the realization that the host immune response is probably crucial for controlling disease progression. This has resulted in significant advances in diagnostic techniques (flow cytometric analysis, clonality studies) and disease staging as well as therapeutic approaches (biologic and targeted therapies), as will be discussed below. Although CTCLs are relatively uncommon lymphoproliferative disorders, these recent advances in the diagnosis and treatment of MF/SS vividly demonstrate the impact of the basic understanding of $\mathrm{T}$ cell function that has led us to strive for more rational, targeted, and, ultimately, effective therapies for these patients.

The origins of the malignant $T$ cell: understanding the role of $T$ cells in skin immune surveillance. What is the origin of the skin-homing behavior of the malignant $\mathrm{T}$ cell in MF/SS? To answer this question, one can look at seminal immunological work on the role of normal skin-homing lymphocytes in skin immune surveillance, recently reviewed in ref. 15 . As mentioned above, $\mathrm{MF} / \mathrm{SS}$ patient $\mathrm{T}$ cells are typically mature memory $\mathrm{CD} 4^{+}$helper $\mathrm{T}$ cells. In normal skin homeostasis, these $\mathrm{T}$ cells are recruited to the skin following injury. Environmental or infectious damage results in keratinocyte cytokine release and also triggers innate immune responses from skin-resident immune cells, such as DCs, mast cells, and macrophages. This response may be mediated by pathogen components (bacterial CpG-oligodeoxynucleotides [CpG-ODNs], cell wall components, and viral DNA and RNA)

\section{Figure 1}

Cutaneous lesions of MF and SS. (A) Hypopigmented patches of MF on the proximal arm. Patches can be pink, red, hypopigmented, or hyperpigmented and are often scaly. (B) Two plaques near the axilla. MF lesions can have annular and gyrate configurations. (C) A tumor on the arm. Tumors frequently ulcerate. (D) Erythroderma in a patient with SS; more than $80 \%$ of his body surface area is affected with confluent erythematous scaly patches.
A

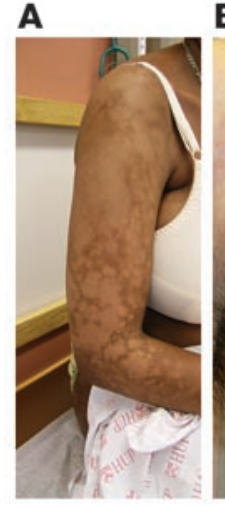

B

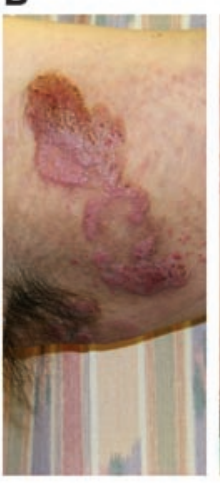

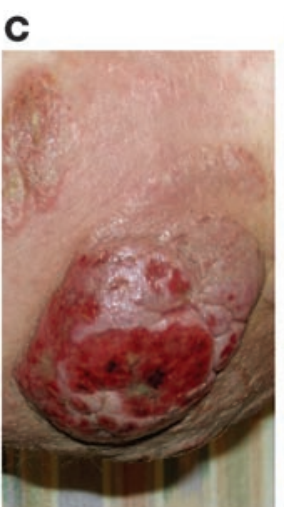

D

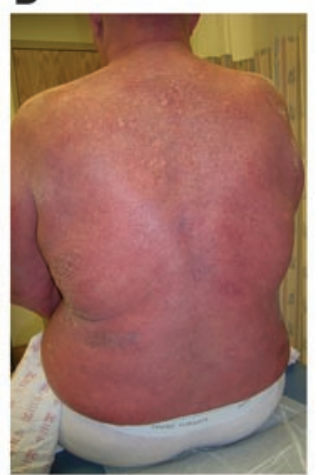




\section{MF variants}

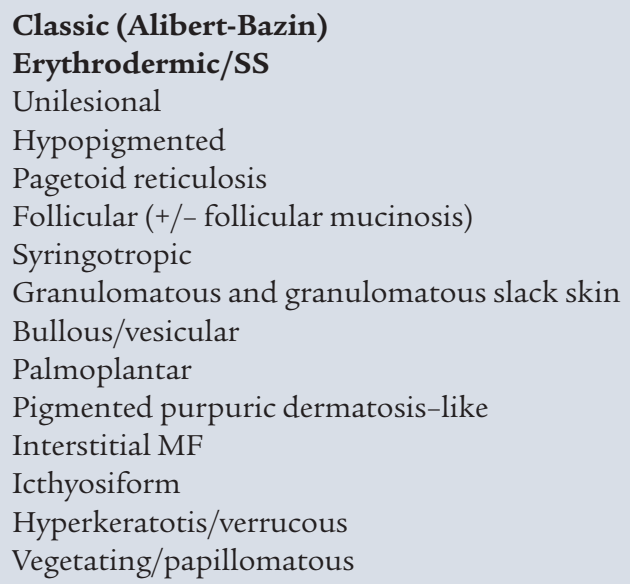

that are recognized by pattern-recognition receptors, most notably the Toll-like receptors (TLRs), on these cells.

The downstream results of the activation of these pathways via upregulation of NF- $\kappa \mathrm{B}$ signaling are proinflammatory responses that have direct effects on pathogens and result in additional inflammatory cell recruitment and migration of activated APCs to local skin-draining lymph nodes. Once these APCs encounter the appropriate naive $\mathrm{T}$ cells in the lymph nodes, adaptive immune surveillance is called into action. The $\mathrm{T}$ cells become antigen-specific effector/memory cells and acquire the ability to home to the original site of inflammation, the skin. Antigenspecific central memory $\mathrm{T}$ cells are subsequently generated and circulate through lymph nodes to provide a long-term reservoir for specific immune surveillance.

These skin effector/memory $\mathrm{T}$ cells express cutaneous lymphocyte antigen (CLA) and normally make up 30\% of all circulating memory $\mathrm{T}$ cells. CLA-expressing skin-homing $\mathrm{T}$ cells can interact with the receptor E-selectin on dermal postcapillary venules. These $\mathrm{CLA}^{+}$cells also typically coexpress CC-chemokine receptor 4 (CCR4), which binds to the skin-manufactured chemokines CC-chemokine ligand 17 (CCL17) (also known as TARC) and CCL22 (also known as MDC), among others. A subset of skin-homing $\mathrm{CLA}^{+} / \mathrm{CCR} 4^{+}$lymphocytes also appear to coexpress CCR10 (16). All of these interactions are also crucial to the rolling/tethering interaction between the $\mathrm{T}$ cell and the endothelium that is necessary for the $\mathrm{T}$ cell to gain entry into the dermis and epidermis. It is believed that these memory skinhoming $\mathrm{T}$ cells can not only respond to skin inflammation and injury but may also actually home to the skin constitutively. The balance between appropriate skin defense responses and inappropriate or dysregulated responses appears to be the key to understanding the pathogenesis and treatment of acquired inflammatory skin conditions, including MF/SS.

The malignant $\mathrm{T}$ cells in MF/SS patients have been shown to express the skin-homing receptors CLA and CCR4 (Figure 3). Furthermore, MF lesions can express high levels of CCL17 and CCL22 $(17,18)$. Other chemokine receptors expressed by skin-infiltrating $\mathrm{T}$ cells found in MF lesions, such as CXC-chemokine receptor 3 (CXCR3) and CXCR4, and surface molecules, such as integrin $\alpha_{\mathrm{E}} \beta_{7}$, have corresponding ligands expressed by epidermal keratinocytes and Langerhans cells. Their expression levels appear to correlate with earlier stage lesions and may reflect cells of the host immune response (19), as tumor stage lesions frequently lose expression of these markers. One can also observe less epidermotropism in the skin biopsies of advanced forms of MF, such as erythrodermic MF and SS. In a study comparing chemokine receptor expression in different stages of MF, tumor-stage tissue demonstrated decreased expression levels of CCR4 or CXCR3 but increased levels of CCR7, a receptor necessary for lymphatic entry (20).

Thus, the MF/SS malignant $\mathrm{T}$ cell clone probably arises out of the normal skin immune surveillance arsenal. Immunohistochemistry and ultrastructural studies have demonstrated that the hallmark Pautrier microabcess seen on histopathology consists of clusters of malignant $\mathrm{T}$ cells surrounding and in contact with Langerhans cells, the immature resident DCs in the skin. Because of these observations, the potential role of the epidermal Langerhans cells in the pathogenesis of MF/SS has been the subject of intense study (21). Epidermal Langerhans cells may be a source of persistent antigenic stimulation of $\mathrm{T}$ cells, resulting in activation and subsequent clonal expansion (22).

The state of activation of the malignant $\mathrm{T}$ cell in MF/SS is evidenced by the constitutive phosphorylation of Stat 3 that is observed (23). In addition, these T cells express CD45RO and proliferating-cell nuclear antigen and may express CD25, the IL-2 $\alpha$ receptor (1). Unlike malignant cells in ATLL, the majority of early MF lesions do not express CD25. However, in more advanced MF/SS, the soluble form of the IL-2 receptor (sIL-2R) can be detected in the blood and has been demonstrated as an important negative prognostic factor (24). Furthermore, Tregs also express CD25, and recent data is emerging to suggest that MF/SS may involve Tregs (see "Immune defects in MF/SS," below).

\section{Table 1}

Lesion terminology in MFA

$\begin{array}{ll}\text { Lesion } & \text { Definition } \\ \text { Patch } & \text { Any size skin lesion without significant elevation or induration; may show pigment changes, scaling, crusting, wrinkling } \\ \text { Plaque } & \text { Any size skin lesion that is elevated or indurated; may show pigment changes, scaling, crusting, or follicular prominence } \\ \text { Tumor } & \text { A solid/nodular lesion }>1 \mathrm{~cm} \text { or ulcerated plaque with evidence of depth and/or vertical growth } \\ \text { Erythroderma } & \text { Confluence of erythematous lesions covering } \geq 80 \% \text { of the body surface area } \\ \text { Erythrodermic MF } & \text { Erythroderma without clinically significant blood involvement } \\ \text { SS } & \text { Erythroderma with clinically significant blood involvement }\end{array}$

AUnpublished 2005 provisional definitions, ISCL. BSee text for the ISCL criteria of blood involvement in MF/SS. 


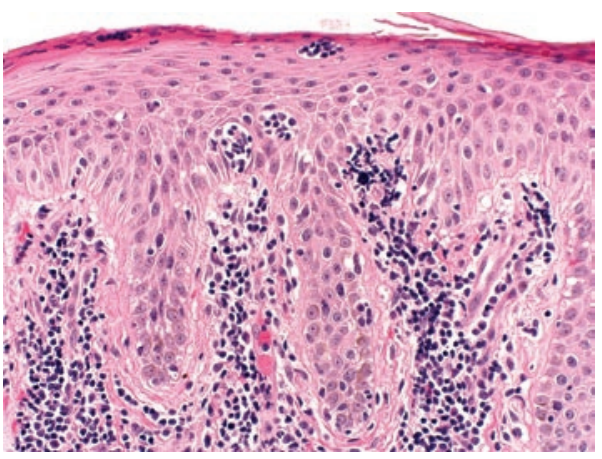

\section{Figure 2}

Histopathology of classic MF. This skin biopsy specimen demonstrates an atypical lymphocytic infilitrate going up into the epidermis (epidermotropism) in the absence of epidermal edema (spongiosis). The collection of atypical lymphocytes surrounding a Langerhans cell is a Pautrier microabcess, the hallmark of classic MF.

Although it is unknown what precisely triggers the constitutive activation of a population of skin-homing, mature $\mathrm{CD} 4^{+} \mathrm{T}$ cells in $\mathrm{MF} / \mathrm{SS}$, this may result in a skewed Th2-cytokine expression profile and subsequent inflammatory disease and immune dysregulation. In patients, this Th2 profile may contribute to disease progression through production of IL-4 and IL-10, which compromise the host immune response (25) (see "Immune defects in MF/SS," below).

Malignant T cell clonality: a new diagnostic tool for MF/SS. As yet, MF/SS has not been clearly associated with a single or specific chromosomal mutation in either tumor suppressor genes or oncogenes. However, disease progression in MF/SS has been associated with several genetic abnormalities that enable a dominant clonal population to emerge. Chromosomal rearrangement hot spots have been detected in MF/SS and include deletions on 1p, 17p, 10q, and 19 and gains at 4q, 18, and 17q (26). Early patch and plaque MF lesions may demonstrate defects in Fas expression or constitutive STAT activation that result in impaired tumor cell apoptosis $(27,28)$. More advanced lesions, such as tumors, have been shown to have p53-expression defects $(29,30)$, microsatellite instability due to hypermethylation of mismatch repair genes, such as $h M L H 1$ (31), and p16/p15 alterations (32).

The clonal nature of MF/SS has been demonstrated by $\mathrm{T}$ cell receptor gene rearrangements ( $\beta$ or $\gamma$ chain rearrangements) detectable by either Southern blotting or PCR analysis. In particular, PCR methods are extremely sensitive and can detect monoclonality even in very early disease (33). However, false-negative PCR testing can occur, especially when the lymphocyte infiltrate in the tissue is sparse. Furthermore, clonal TCR gene rearrangements can be demonstrated in a variety of benign inflammatory skin conditions (34) and occasionally in controls. In addition, the nonmalignant skin-infiltrating lymphocytes seen in MF lesions could also be an oligoclonal or monoclonal population and contribute to positive gene rearrangement results. Because of this, the presence of monoclonality by molecular testing should not be automatically equated with neoplasia.

Nonetheless, demonstration of clonality in skin lesions of MF/SS patients has become an established component of the diagnostic evaluation of patients and may be helpful, especially in early MF cases. In particular, for each patient, in the appropriate clinical and histopathological context, the ability to demonstrate the same clonal population in more than one skin lesion or in the skin, the lymph node, and the peripheral blood as well as longitudinally is viewed as significant. Microdissection of tumor cells can increase the sensitivity of detection $(35,36)$. In addition, PCR testing for clonality may be useful in detecting minimal residual disease after treatment (37).

In advancing disease, expansion of the malignant clone in the peripheral blood results in a concomitant decrease in the normal lymphocyte populations, in particular cytotoxic CD8 ${ }^{+}$ $\mathrm{T}$ cells and $\mathrm{CD} 6^{+} \mathrm{NK}$ cells as well as both myeloid and plasmacytoid DCs. Quantification of the peripheral blood tumor burden was traditionally accomplished by manual examination of a peripheral blood buffy coat smear for the malignant Sézary cells. As mentioned earlier, this method is not highly sensitive or accurately reproducible among different laboratories (11). Activated normal lymphocytes can look phenotypically similar to the atypical Sézary cells. More specific and sensitive means of detecting the malignant $T$ cells include using anti-TCR V $\beta$-specific monoclonal antibodies (38) or antibodies to other relevant T cell surface markers (e.g., CD3, CD4, CD8, CD7, and CD26) (9) and using fluorescence-activated cell-sorting analysis/flow cytometry. Flow cytometry has largely supplanted the Sézary count for the evaluation of MF/SS patient blood involvement in most medical centers.

The 1978 National Cancer Institute staging system for MF divides the B (Blood) classification into B0 (no circulating atypical cells) and B1 (circulating atypical cells) (see TNMB classification for $M F$ and SS). To reflect the above advances in detecting peripheral blood involvement, updated criteria for significant blood involvement in erythrodermic patients was proposed by the ISCL in 2002 (11). The B classification was expanded to include B0 (no clinically significant blood involvement), B1 (clinically significant nonleukemic involvement, with Sézary cells $<1.0 \mathrm{~K} / \mu \mathrm{l}$ ), and B2 (leukemic involvement as indicated by [a] Sézary cells $\geq 1.0 \mathrm{~K} / \mu \mathrm{l}$; [b] CD4/CD8 ratio > 10 with $\mathrm{CD}^{+} \mathrm{CD}^{-}$population $>40 \%$ or

\section{TNMB classification for MF and SS}

\section{T (skin)}

T1 Limited patch/plaque ( $<10 \%$ body surface area)

T2 Generalized patch/plaque ( $\geq 10 \%$ body surface area)

T3 Tumors

T4 Generalized erythroderma

\section{N (lymph node)}

No Clinically uninvolved

N1 Clinically abnormal, histologically uninvolved

N2 Clinically uninvolved, histologically involved

N3 Clinically abnormal, histologically involved

\section{M (viscera)}

M0 No visceral involvement

M2 Visceral involvement

B (blood)

B0 No circulating atypical (Sézary) cells

B1 Circulating atypical (Sézary) cells

See ISCL 2002 consensus report on the B classification changing this to B0, $\mathrm{B} 1, \mathrm{~B} 2$ as discussed in "The origins of the malignant T cell." Adapted with permission from Hematology/Oncology Clinics of North America (11). 


\begin{tabular}{l} 
Table 2 \\
Clinical staging system for MF and SS, National Cancer Institute \\
Workshop 1978 \\
\hline
\end{tabular}

\section{Clinical Stages}

\begin{tabular}{lccc} 
IA & T1 & N0 & M0 \\
IB & T2 & N0 & M0 \\
IIA & T1-2 & N1 & M0 \\
IIB & T3 & N0-1 & M0 \\
IIIA & T4 & N0 & M0 \\
IIIB & T4 & N1 & M0 \\
IVA & T1-4 & N2-3 & M0 \\
IVB & T1-4 & N0-3 & M1 \\
\hline
\end{tabular}

Adapted with permission from Hematology/Oncology Clinics of North America (11).

$\mathrm{CD}^{+} \mathrm{CD} 26^{-}$population > 30\%; [c] lymphocytosis with molecular genetic evidence of a $\mathrm{T}$ cell clone; or [d] evidence of a chromosomally abnormal $\mathrm{T}$ cell clone) (39).

More recent work has suggested that MF/SS patients not only have clonal expansion of the malignant population of $\mathrm{T}$ cells, but that their entire $T$ cell repertoire may be profoundly disrupted. $\beta$-variable-complementarity-determining region 3 spectratyping studies of the peripheral blood of MF/SS patients revealed decreased complexity of the $\mathrm{T}$ cell repertoire, reminiscent of spectratype patterns observed among patients with advanced HIV infection (40). This reduction of TCR complexity was observed among virtually all advanced-stage patients as well as among $50 \%$ of patients with even the earliest stages of MF. The true significance of this finding in early-stage patients remains unclear, but it certainly provides partial explanation of the immunosuppression and susceptibility to infectious agents seen in advanced MF and SS cases. Furthermore, the authors of this study suggest that a factor, either infectious or produced as a soluble agent by the malignant $T$ cells, compromises the growth of normal $\mathrm{T}$ cell populations. Potential candidates that have been suggested include a member of the Th2 cytokine family, TGF- $\beta$, or a retrovirus $(21,40)$.

Immune defects in MF/SS: Th2 predominance and clues to understanding disease progression. The malignant $\mathrm{CD}^{+} \mathrm{T}$ cells observed in most cases of MF/SS appear to exhibit a Th2 phenotype (Figure 4). In vitro stimulation of peripheral blood cells derived from SS patients routinely results in increased levels of measurable IL-4 expression (25). Moreover, Vowels et al. demonstrated levels of IL-4 and IL-5 mRNA in clinically involved skin, even among patients with early patches or plaques, while uninvolved skin and the skin of normal volunteers did not have detectable levels of Th2 cytokine mRNA (41). Assadullah et al. were also able to demonstrate increasing levels of IL-10 mRNA in parallel with an increasing density of the malignant $\mathrm{T}$ cell infiltrate as lesions progressed from patch to plaque to tumor (42). In SS, Th2 cell-specific transcription factors, such as GATA-3 and Jun B are highly overexpressed, as detected by cDNA microarray analysis (43). Thus, despite evidence of a vigorous host response in skin lesions in early disease, characterized by the presence of IFN- $\gamma$-secreting $\mathrm{CD}^{+} / \mathrm{TiA}^{-} 1^{+} \mathrm{T}$ cells (44), the chronic production of Th2 cytokines, such as IL-4, IL-5, and IL-10 by the malignant T cell population likely represents one mechanism by which the tumor cells circumvent the antitumor immune response.
Even in advanced disease, the host response, although effete, may play a role, albeit small, in containment of disease progression. This has been evidenced by the rapid progression of SS associated with the use of immunosuppressive agents, such as cyclosporine (45). In addition to enhanced Th2 cytokine production during disease progression, patients with overt evidence of circulating malignant $\mathrm{T}$ cells also manifest defects in Th1 cytokine production. Wysocka et al. observed a progressive decline in the production of IL-12 and IFN- $\alpha$ by peripheral blood cells that paralleled an increase in the peripheral blood burden of malignant $T$ cells (46). The decline in production of these cytokines directly correlated with a decline in the numbers of peripheral blood myeloid and plasmacytoid DCs, respectively. Accompanying the decrease in DCs and a defect in IL-12 production is a presumed deficit in production of other products of myeloid DCs, including IL-15 and IL-18, all of which are important IFN- $\gamma$-stimulating agents and powerful boosters of Th1 responses. Indeed, peripheral blood cells of leukemic CTCL patients clearly manifest marked decreases in IFN- $\gamma$ production in response to a multiplicity of stimuli (25).

Underlying the decline in Th1 cytokine production and numbers of circulating DCs is the enhanced Th2 cytokine production that can compromise both DC maturation and IL-12/IFN- $\gamma$ production (47). Other mechanisms responsible for diminished IL-12 production have been highlighted by recent studies by French et al., which demonstrated a defect in expression of CD40 ligand on malignant $\mathrm{T}$ cells derived from patients with SS (48). CD40 ligand is not expressed on resting T cells but is normally upregulated on the cell surface upon engagement of the TCR. By contrast, malignant $\mathrm{CD} 4^{+} \mathrm{T}$ cells fail to express CD40 ligand upon engagement of the TCR by anti-CD3. Clearly, the absence of CD40 ligand interaction with CD40 on APCs during an immune response can lead to a profound reduction in DC activation and cytokine production. Through the in vitro addition of recombinant hexameric CD40 ligand, French and colleagues demonstrated reconstitution of IL-12 and TNF production by the cells of patients with SS (48). These findings provide obvious insights regarding potential strategies for circumventing the immune deficiency associated with advancing MF/SS.

Recently, Berger et al. demonstrated that under certain in vitro conditions, malignant $\mathrm{CD} 4^{+} \mathrm{T}$ cells derived from patients with CTCL can be induced to demonstrate a CD $25^{+}$Treg phenotype (49). Thus, when malignant T cells are cultured with DCs that have had the opportunity to process significant numbers of apoptotic $\mathrm{T}$ cells, they upregulate cytotoxic $\mathrm{T}$ lymphocyte antigen 4 (CTLA-4) expression, express Foxp3, and develop the enhanced capacity to produce IL-10 and TGF- $\beta$. Previously, only peripheral blood cells derived from ATLL patients who were infected with HTLV-1 were observed to have similar Treg

\section{Table 3}

Five-year survival of MF/SS patients as reported by a single center, retrospective cohort study

$\begin{array}{lc}\text { Stage } & \text { 5-year survival (\%) } \\ \text { IA } & 96 \\ \text { IB/IIA } & 73 \\ \text { IIB/III } & 44 \\ \text { IV } & 27\end{array}$

Adapted with permission from Archives of Dermatology (5). 

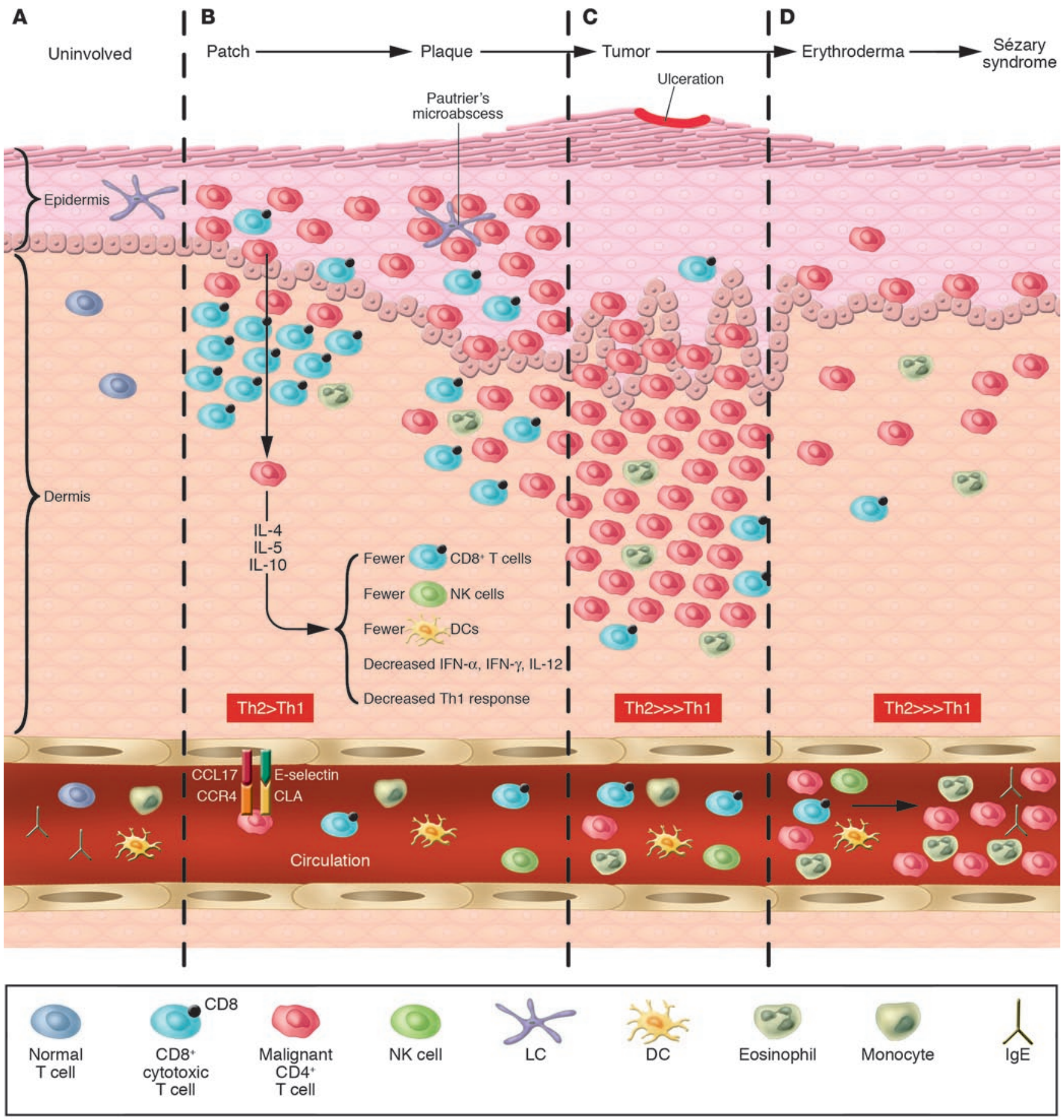

\section{Figure 3}

The skin microenvironment in MF progression. (A) Normal skin showing resident Langerhans cells in the epidermis and skin-homing T cells in the dermis and circulation. (B) Patch and plaque MF in which the CD4+ malignant T cells home to the epidermis and collect around Langerhans cells. Of note, in these stages, the epidermal and dermal infiltrate frequently have abundant CD8 ${ }^{+} \mathrm{T}$ cells as part of the host immune response. (C) Tumor MF in which the tumor occupies the dermis and subcutaneous tissue and is comprised of primarily malignant T cells and few CD8 ${ }^{+}$ T cells. (D) Erythrodermic MF and SS with detectable circulating malignant T cells that elaborate Th2 cytokines that affect CD8+ T cell, NK cell, and DC numbers and function, and consequently, the host immune response.

characteristics (50). If indeed MF/SS is a tumor of Tregs, this may be an additional compelling explanation behind the immunosuppression seen in advanced disease.
The end results of alterations in cytokine expression pathways during progressive $\mathrm{MF} / \mathrm{SS}$ are multiple abnormalities in cellular immunity (Figure 5). Our group routinely observes defects in cellu- 

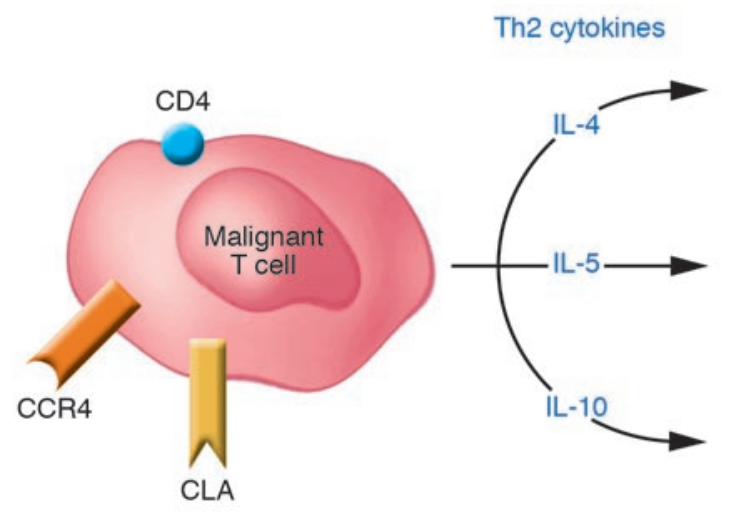

Increased $\lg \mathrm{E}$ Decreased Th1 effects

Eosinophilia

Decreased Th1 effects

Decreased cell-mediated immunity

Decreased dendritic cells

\section{Figure 4}

Consequences of malignant $T$ cell cytokine production. In MF/SS, the malignant $T$ cell $\left(\mathrm{CD} 4^{+} / \mathrm{CLA}^{+} / \mathrm{CCR} 4^{+}\right)$produces the cytokines IL-4, IL-5, and IL-10 that result in a Th2 predominance and subsequent multiple abnormalities in cellular immunity. lar cytotoxicity that correlate with the burden of circulating malignant T cells (51). Progression from early to more advanced MF/SS is typically associated with a marked decline in NK cell numbers and activity. Similarly, a decline in the number of peripheral blood $\mathrm{CD}^{+} \mathrm{T}$ cells accompanies an increasing burden of circulating malignant T cells. Furthermore, the percentage of these cytotoxic cells that express activation markers, such as CD69, is also significantly reduced compared to that of $\mathrm{NK}$ and $\mathrm{CD}^{+} \mathrm{T}$ cells from $\mathrm{MF}$ patients without overt peripheral blood involvement (52). A reduction in the number of functioning $\mathrm{NK}$ and $\mathrm{CD} 8^{+} \mathrm{T}$ cells is almost certainly associated with a deterioration of both host antitumor immunity and immune surveillance against microbial organisms. Examples of these phenomena include infections such as disseminated herpes simplex/zoster among SS patients who have never been iatrogenically immunosuppressed by chemotherapy or other immunosuppressive medications $(53,54)$. Secondary melanoma and nonmelanoma skin cancers may also be more common in $\mathrm{MF} / \mathrm{SS}$ patients independent of the history of previous predisposing therapy (such as phototherapy or radiation therapy) $(55,56)$.

Other characteristic immunological findings associated with the progression of MF/SS include development of peripheral eosinophilia and elevated levels of serum $\operatorname{IgE}(25,57)$. Peripheral eosinophilia has been determined to be an independent marker for poor prognosis and disease progression (58). In one study, peripheral blood cells from patients with SS and eosinophilia produced markedly higher levels of IL-5 upon stimulation than did the cells of patients or normal volunteers without eosinophilia (59). It is noteworthy that in this study, culture of the patients' cells with either recombinant IFN- $\alpha$ or IL-12 significantly inhibited the excess production of IL-5. These findings suggest that these cytokines could be useful therapeutic tools for preventing continued proliferation of eosinophils under the influence of IL-5, thus possibly preventing at least some of the adverse effects associated with high eosinophil counts.

It is particularly important to stress that after successful treatment of SS, with clearance of the skin erythroderma and disappearance of the malignant clone from the blood, virtually all abnormal immune parameters are restored to normalcy (Figure 5) (51). One implication of these observations is that the malignant clone is probably responsible for much of the immune dysregulation that occurs in SS. Moreover, these findings indicate that SS patients who experience remission will have their immune systems at least partially reconstituted. Thus, such patients should be less likely to experience severe consequences of microbial infection in comparison with those with advanced SS.

\section{Current and emerging therapies for MF: a multimodality approach}

Early stage MF. A variety of skin-directed and systemic therapies are available to treat MF/SS (Table 4), and the stage of disease guides the therapeutic choices (Table 5). In the past, traditional systemic chemotherapy has not resulted in durable remissions in MF/SS. As a consequence, emerging therapeutic efforts have focused upon targeted biological agents and manipulation of the host immune response using a multimodality approach. Numerous arms of the immune system must cooperate to generate a sufficient host antitumor response such that the proliferation of the malignant $\mathrm{T}$ cell population in MF/SS patients can be controlled and, ideally, eradicated (Figure 6).

Patients with patches or plaques limited to less than $10 \%$ of their skin surface area ( $\mathrm{T} 1$ disease) tend to exhibit normal cellular immune responses. Thus, use of skin-directed therapies, such as superpotent topical corticosteroids, topical chemotherapy $(60,61)$, topical retinoid application (62), psoralen plus ultraviolet A phototherapy (PUVA) (63), or electron beam radiation therapy (64), which target

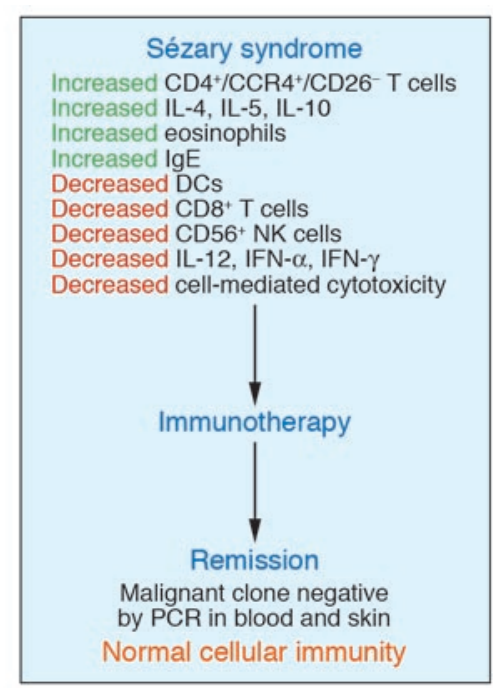

\section{Figure 5}

Elimination of the malignant $\mathrm{T}$ cell clone during immunotherapy leads to a restoration of a normal immune response. Studies of numerous patients with SS have demonstrated that induction of complete remission with clearing of the malignant $\mathrm{T}$ cell clone during multimodality immunotherapy leads to a restoration of normal host immune function. 


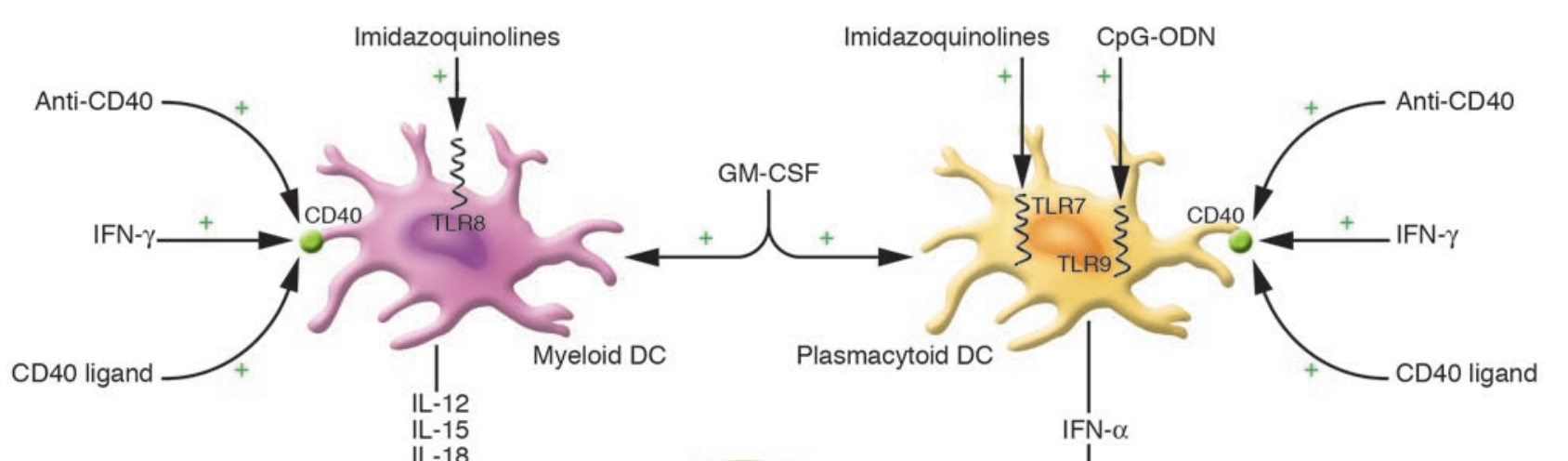

IL -15
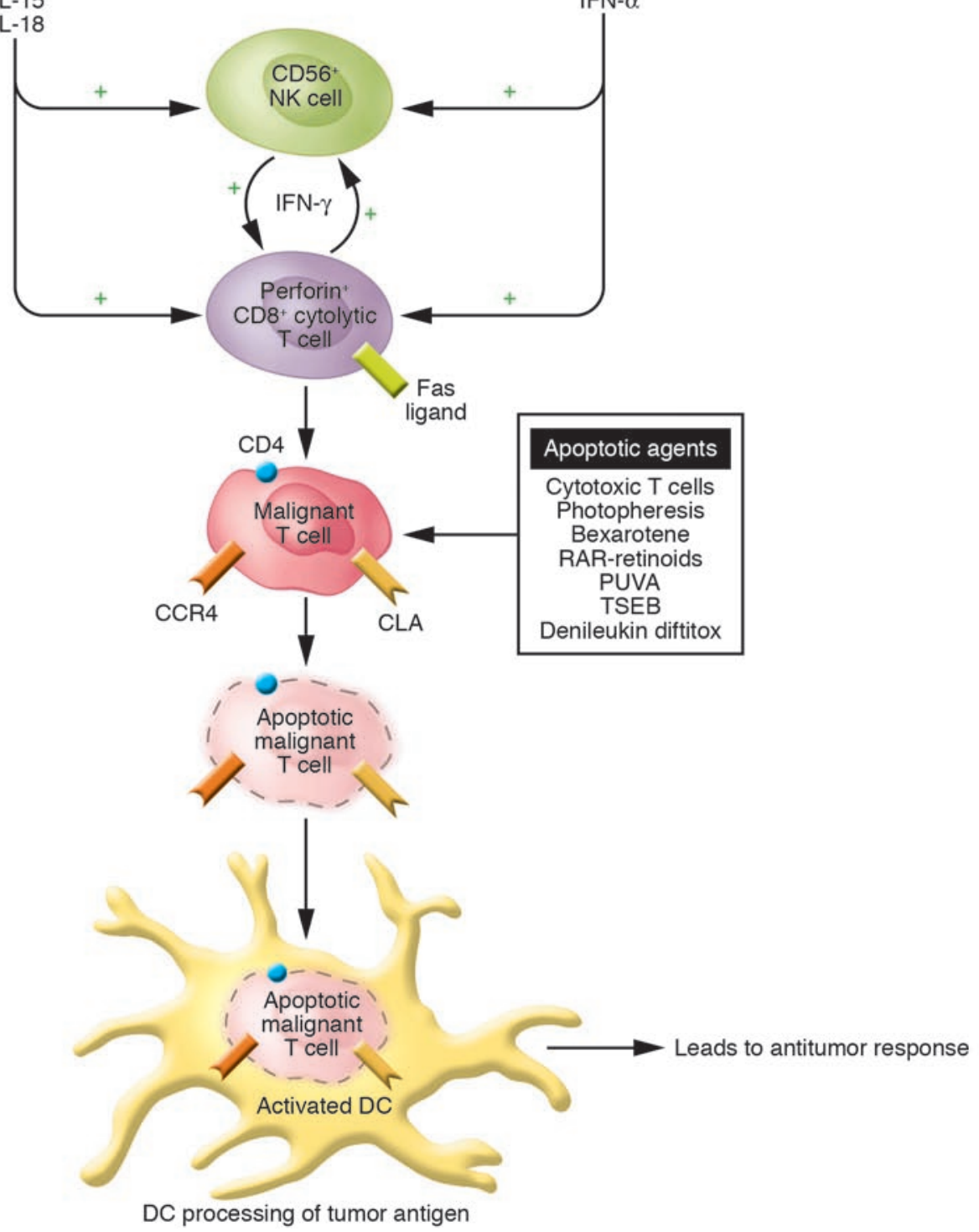

Figure 6

Multimodality strategy for enhancing the antitumor response using immunotherapeutics. A multimodality approach encompasses the activation of multiple arms of the immune response through the use of agents to activate DCs, CTLs (CD8+), and NK cells (CD56+). GM-CSF may enhance the numbers of DCs while agents that enhance CD40 expression (IFN- $\gamma$ ) and activation (CD40 ligand; activating anti-CD40 antibody) and TLR ligands (CpG-ODNs; imidazoquinolines) lead to DC cytokine production and to enhanced DC processing of apoptotic malignant T cells. Cytokines produced by DCs as well as exogenously administered cytokines augment $C D 8^{+} T$ cell and possibly NK cell cytolytic activity against the tumor cells. RAR-specific retinoids stimulate DC and CD8 ${ }^{+} \mathrm{T}$ cell cytokine production. Proapoptotic agents, including bexarotene, RAR-specific retinoids, PUVA, photopheresis, topical chemotherapy, total skin electron beam irradiation (TSEB), and denileukin diftitox, can assist in the development of an antitumor immune response by reducing the overall tumor burden and by providing a source of apoptotic malignant cells and tumor antigens for uptake by DCs. 
Table 4

Treatment options in MF/SS

\section{Skin-directed therapy \\ Topical corticosteroids \\ Topical chemotherapy (nitrogen mustard, BCNU) \\ Topical retinoids (bexarotene, tazarotene) \\ Topical imiquimod \\ Phototherapy (UVB, PUVA) \\ Electron beam therapy \\ Biological therapy \\ RXR retinoid (bexarotene) \\ RAR retinoid \\ (isotretinoin, all-trans-retinoic acid)}

IFN- $\alpha$ and IFN- $\gamma$

\section{GM-CSF}

ECP

Fusion protein/toxin (denileukin diftitox)

\section{Other systemic therapy}

Cytotoxic chemotherapy (Methotrexate, Doxil, gemcitabine, etoposide, pentostatin)

Bone marrow/stem cell transplantation

\author{
Experimental therapy \\ Transimmunization ECP \\ Targeted monoclonal antibodies \\ (CD4, CD52, CD40, CCR4) \\ HDACs (SAHA, depsipeptide) \\ Cytokines (IL-12, IL-2, IL-15) \\ TLR agonists (CpG-ODNs, imidazoquinolones)
}

Tumor vaccines

\author{
Mechanism of action \\ Tumor cell apoptosis; decreases skin LCs \\ Tumor cell apoptosis \\ Tumor cell apoptosis \\ TLR-7 agonist; triggers innate and \\ adaptive antitumor immunity \\ Tumor cell apoptosis \\ Decreases skin LCs \\ Tumor cell apoptosis \\ Tumor cell apoptosis \\ Inhibits tumor cell IL-4 production \\ Tumor cell apoptosis \\ Induces IFN- $\gamma$ \\ Enhances cell-mediated cytotoxicity \\ Inhibits tumor cell Th2 cytokine production \\ Inhibits tumor cell proliferation \\ Enhances circulating DC numbers and function \\ Circulating tumor cell apoptosis \\ Induces DC differentiation \\ Targets and kills CD25-expressing \\ (IL-2 receptor-expressing) tumor cells
}

Cytotoxic agents

Cytotoxic agents (induction) Graft-versus-tumor effect

Enhances antigen processing of apoptotic tumor cells by DCs Target tumor cells (CD4, CD52, CCR4)

Activate DCs (CD40)
Inhibit gene transcription
Augment cell-mediated antitumor immunity
Augment innate and adaptive
antitumor immunity
Clonotypic TCR as antigen
DC-based vaccines

LC, Langerhans cell; BCNU, bischloroethylnitrosourea; UVB, ultraviolet B; SAHA, suberoylanilide hydroxamic acid.

the vast majority of the tumor burden in the skin by directly inducing apoptosis of malignant $\mathrm{T}$ cells, is often sufficient to induce complete clearing of disease. Topical corticosteroids and PUVA also decrease the number of resident epidermal Langerhans cells and subsequently interrupt their chronic stimulation of the malignant $\mathrm{T}$ cells. At this stage, the systemic immune response is intact and, along with other factors, may contribute to controlling disease burden so that it does not extend beyond the skin. In the event that clearing is not complete, the addition of a single agent systemic immunomodulator, such as recombinant IFN- $\alpha$ or the retinoid bexarotene (Targretin), typically leads to a better clinical response.

For patients who do not yet manifest overt peripheral blood disease but who exhibit more extensively infiltrated cutaneous plaques on a greater skin surface area, combined therapeutic approaches appear to result in more rapid responses (65-68). IFN- $\alpha$, produced by plasmacytoid DCs, is a product of the innate immune response, and appears to be one of the most highly active biologic agents used in the therapy of MF/SS (69). As suggested above, it is well accepted that treatment with PUVA plus IFN- $\alpha$ administration can produce higher clinical response rates than the use of PUVA alone $(68,70)$. Several small studies have also suggested that a combination of IFN- $\alpha$ with oral retinoids, including bexarotene or 13-cis retinoic acid, may induce rapid responses among patients with extensive skin lesions $(65,71)$.

IFN- $\alpha$ induces a variety of salutary immunological effects that may lead to disease clearing. IFN- $\alpha$ directly enhances cell-mediated cytotoxicity; both $\mathrm{CD}^{+} \mathrm{T}$ cells and NK cells exhibit rapid activation as assessed by upregulation of CD69, and the cytotoxic effects of NK cells are significantly augmented (52). IFN- $\alpha$ also suppresses Th2 cytokine production by malignant $\mathrm{T}$ cells, which can lead to enhanced immunomodulation.

Bexarotene, a retinoid $\mathrm{X}$ receptor-specific compound recently approved by the FDA, has also been determined to have valuable immunomodulatory effects that are of benefit in the treatment of MF/SS, particularly when used in combination therapy. Bexarotene has the ability to induce apoptosis within the malignant population of $\mathrm{T}$ cells $(72,73)$. This effect may account for the nearly $50 \%$ response rate of $\mathrm{MF} / \mathrm{SS}$ patients when high-dose, single-agent oral bexarotene is administered (74). Nevertheless, Budgin et al. have demonstrated that, although the malignant cells of most patients with SS are susceptible to the apoptotic effects of bexarotene in vitro, purified Sézary cells from approximately one-third of patients demonstrate significant resistance to apoptosis (73). This finding may account for the failure of a subset of patients to respond clinically to this compound. Bexarotene also has the capacity to inhibit IL-4 production, and possibly that of other Th2 cytokines, in vitro, by peripheral blood cells of SS patients. The net effect would be to negate the suppressive effects of these cytokines on cellular immunity.

In contrast to bexarotene, retinoic acid receptor-specific (RARspecific) retinoids may have modest direct immune potentiating properties. Using a number of different RAR-specific retinoids, including all-trans-retinoic acid and 13-cis-retinoic acid, Fox et al., demonstrated that these compounds exhibited the capacity to induce IL-12-dependent IFN- $\gamma$ production (75). Moreover, synergistic production of IFN- $\gamma$ occurred when low concentrations of IL-2 were added to the RAR-specific retinoids. In contrast, bexarotene does not induce IFN- $\gamma$ production (73). These 
Table 5

Treatment of MF/SS by clinical stage

\begin{tabular}{|c|c|c|c|}
\hline Stage & Initial therapy & Subsequent therapy & Therapy for refractory disease \\
\hline IA & Skin-directed therapies & & \\
\hline $\mid \mathrm{B} / \mathrm{II}$ & $\begin{array}{l}\text { Topical chemotherapy } \\
\text { Phototherapy } \\
\text { Electron beam therapy } \\
\text { (+/- low-dose biological agents) }\end{array}$ & $\begin{array}{l}\text { IFNs } \\
\text { Retinoids } \\
\text { Multimodality therapy } \\
\quad \text { Topical chemotherapy + biological agent } \\
\quad \text { Phototherapy + biological agent } \\
2 \text { biological agents } \\
\text { Denileukin diftitox }\end{array}$ & Experimental therapies \\
\hline IIB & $\begin{array}{l}\text { Few tumors } \\
\text { Localized EBT } \\
\text { Intralesional IFN } \\
\text { Topical chemotherapy + biological agent } \\
\text { Generalized tumors } \\
\text { Total skin EBT } \\
\text { Denileukin diftitox } \\
\text { Multimodality therapy }\end{array}$ & $\begin{array}{l}\text { Multimodality therapy } \\
\text { Denileukin diftitox } \\
\text { Single-agent chemotherapy }\end{array}$ & Experimental therapies \\
\hline IIIA, B & $\begin{array}{l}\text { PUVA } \\
\text { Retinoids } \\
\text { IFNs } \\
\text { Methotrexate } \\
\text { ECP } \\
\text { Multimodality therapy }\end{array}$ & $\begin{array}{l}\text { Multimodality therapy } \\
\text { Denileukin diftitox } \\
\text { Single-agent chemotherapy }\end{array}$ & Experimental therapies \\
\hline IVA, B & $\begin{array}{l}\text { Single-agent systemic therapy } \\
\text { Multimodality therapy } \\
\text { (+ skin-directed therapy) }\end{array}$ & $\begin{array}{l}\text { Adjuvant palliative local radiation } \\
\text { for extracutaneous disease } \\
\text { Bone marrow/stem cell transplant } \\
\text { Chemotherapy }\end{array}$ & Experimental therapies \\
\hline
\end{tabular}

findings support the use of an RAR-specific retinoid as another component of the combined therapeutic approach.

\section{Advanced MF and SS}

Current therapies. In marked contrast to patients with early MF, patients with advanced MF/SS manifest abnormalities of virtually every arm of the immune response that participates in antitumor immunity (CD8 ${ }^{+} \mathrm{T}$ cells, NK cells, and DCs). Thus, more aggressive therapy is required at these later stages of $\mathrm{MF} / \mathrm{SS}$ to adequately reinvigorate the host response. Accordingly, evidence is now emerging indicating that multimodality immunotherapy using biologic agents can frequently induce complete clinical responses in advanced disease that are both durable and sufficient to eradicate the malignant clone $(51,76,77)$.

As shown in Figure 6, central to the strategy for elimination of the malignant $T$ cell population is the use of agents that can induce apoptosis of these cells while simultaneously enhancing the host's ability to process the apoptotic cells so that a robust cytotoxic T cell response can be generated. For patients with circulating malignant $\mathrm{T}$ cells, extracorporeal photopheresis (ECP) can result in massive apoptosis of cells within the peripheral blood $(78,79)$. ECP is a leukapheresis procedure approved by the FDA for the treatment of SS, in which approximately $10^{10}$ peripheral blood mononuclear cells are collected from the patient, treated with 8-methoxypsoralen, and exposed to 1-2 Joules of ultraviolet A light in the photopheresis machine, then reinfused back to the patient. In addition to inducing malignant $\mathrm{T}$ cell apoptosis, ECP also induces monocytes to differentiate into DCs capable of phagocytosing and processing the apoptotic tumor cell antigens. Repeated cycles of ECP for 2 consecutive days every 3 to 4 weeks with readministration of the treated cells is occasionally sufficient to induce a complete clinical response in SS. One potential modification to ECP, called transimmunization, is currently being studied; during ECP, the apoptotic malignant $T$ cells and the newly formed DCs are coincubated prior to reinfusion to optimize the above antigen processing and stimulate a more efficient induction of tumor-targeted immunity (80).

Nevertheless, administration of large numbers of apoptotic cells as generated by ECP can compromise certain APC functions, including cytokine production, and therefore, has the potential to exacerbate the preexisting immune depressed state (81). Such observations support the rationale for the adjunctive use of multiple agents that can enhance both the afferent immune response and events related to processing of apoptotic malignant cells, as well as therapeutics that will boost the efferent response or the direct cytolytic attack on the tumor cells.

In support of this approach, Richardson and colleagues have recently demonstrated high response rates in SS patients when ECP was combined with the administration of multiple immune adjuvants (76). As part of this regimen, IFN- $\alpha$ and bexarotene were routinely used in combination with ECP. In some cases, GM-CSF 


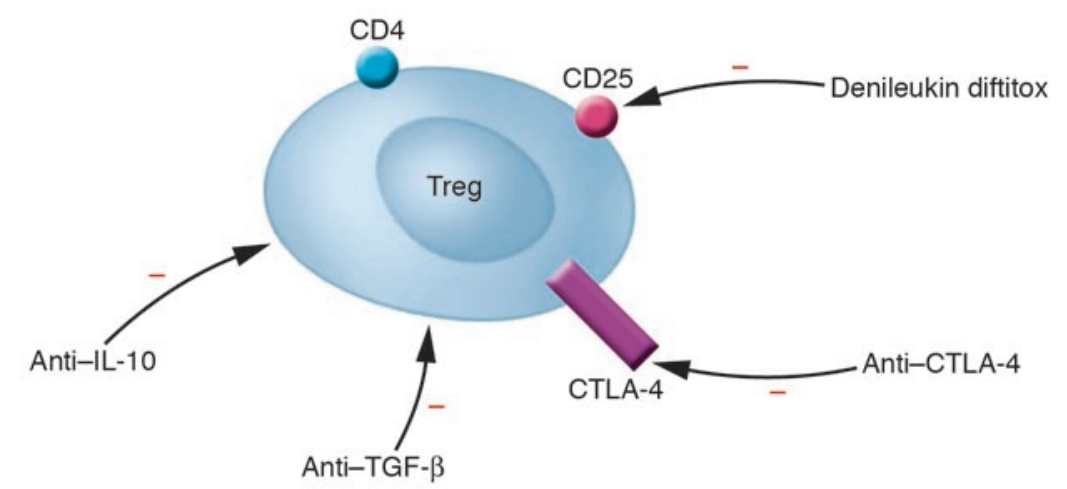

\section{Figure 7}

Inhibiting the effects of regulatory T cells. By inhibiting soluble factors produced by regulatory $T$ cells, preventing CTLA-4 engagement of CD80 or CD86, and inducing apoptosis of regulatory $T$ cells by agents such as denileukin diftitox, the overall effects of regulatory $T$ cells on the immune response can be diminished. was administered following each ECP treatment to enhance APC function. The monthly administration of $125 \mu \mathrm{g}$ of GM-CSF on 2 consecutive days resulted in significant increases in circulating DC numbers compared with DC numbers in ECP-treated SS patients who did not receive GM-CSF (46). In one patient, administration of GM-CSF 3 times per week for 6 months resulted in the persistent normalization of DC numbers, indicating that APC functions might be markedly augmented in this patient population with the long-term use of GM-CSF.

In addition to IFN- $\alpha$, other approaches to enhancing the effector phase of antitumor immunity are presently being utilized (Figure 6). Although limited studies have been reported following the administration of recombinant IFN- $\gamma$, emerging evidence suggests that it has significant potential for the treatment of MF/SS, and it is clearly better tolerated than IFN- $\alpha$, particularly by the elderly, who experience frequent cognitive dysfunction and fatigue with IFN- $\alpha$ treatment (82). In addition to enhancing the cytolytic lymphocyte function of patients with MF/SS, IFN- $\gamma$ suppresses excess Th2 production, enhances CD40 expression, and primes abnormal DCs for IL-12 production, particularly in response to CD40 ligation (46). In the Cutaneous Lymphoma Program at the University of Pennsylvania, when possible, IFN- $\gamma$ is routinely used for SS patients who appear to be refractory to IFN- $\alpha$. In several cases, addition of IFN- $\gamma$ to a multimodality regimen that included photopheresis and bexarotene appeared to be associated with the induction of a sustained complete clinical response (82).

Alternative mechanisms exist for the administration of IFN- $\gamma$. In a small pilot study, Dummer and colleagues demonstrated clinical efficacy of IFN- $\gamma$ cDNA administered subcutaneously in an adenoviral vector (83). The local intralesional injection resulted in significant response rates of individual lesions in both MF and SS patients. Moreover, elevated serum levels of IFN- $\gamma$ were observed and appeared to be associated with regression of lesions distant from the injection sites. This study further suggests that elevation of IFN- $\gamma$ levels can beneficially alter disease progression.

Current therapy but a new potential mechanism: elimination of Treg activity. Although evidence for enhanced $\mathrm{CD} 4^{+} \mathrm{CD} 25^{+}$Treg function in CTCLs is just beginning to emerge (49) and strategies for the elimination of suppressor activity in these diseases remains untested, several potential approaches are possible (Figure 7). Currently, denileukin diftitox (Ontak), a diptheria toxin-IL-2 protein conjugate, is available for targeting IL-2 receptor-bearing T cells (84). After binding to the IL-2 receptor, it undergoes endocytosis followed by release of the diptheria toxin, which results in arrest of protein synthesis and, ultimately, apoptosis of T cells. Intravenous administration of denileukin diftitox to patients with MF results in the regression of plaques and tumors (85). Its major mechanism of action is thought to be mediated by direct killing of malignant T cells. However, it is entirely possible that at least a portion of its activity is mediated through the elimination of CD25-bearing Tregs.

Because Tregs express CTLA-4, another potential approach to their inhibition is through the use of anti-CTLA-4 antibody (86). This therapeutic approach for CTCL remains untested so far. Tregs may also suppress immunoreactivity by production of IL-10 or TGF- $\beta$. Antibodies with neutralizing activity for these factors could be utilized to reverse their inhibitory effects on the immune response.

Emerging immunomodulatory therapies. Numerous alternative strategies exist for the enhancement of APC function (Figure 6). These include the administration of a variety of TLR ligands, which are presently in clinical development $(87,88)$. Imiquimod, a member of the imidazoquinoline family, which has been approved by the FDA for the treatment of basal cell carcinoma, actinic keratoses, and condyloma, has recently been demonstrated to exhibit substantial clinical activity when applied topically to skin lesions of MF patients $(89,90)$. Imiquimod potently triggers TLR-7, which results in IFN- $\alpha$ and TNF- $\alpha$ production $(91,92)$. Imiquimod may also directly induce cells of some tumor types to undergo apoptosis (93).

Several newer members of the imidazoquinoline family have the capacity to trigger TLR-8 in addition to TLR-7 (94). This would be expected to result in a broader activation of both myeloid and plasmacytoid DCs with the release of a more extensive array of immune-activating cytokines. Thus, such compounds would likely broadly activate multiple compartments of the immune response and make newer members of the imidazoquinoline family highly desirable compounds to use as systemic therapeutic agents either alone or as part of a multimodality approach.

Clinical investigation has turned to the effects of an alternative class of DC-activating agents, CpG-ODNs. CpG-ODNs have been recognized as immune stimulatory agents by virtue of activation of DCs following binding to TLR-9 (95). The immunostimulatory potential of $\mathrm{CpG}-\mathrm{ODN}$ s has been tested in murine tumor models and has been observed to lead to the generation of strong antitumor $\mathrm{T}$ cell responses resulting in complete remission of certain established solid tumors (96). Thus, there is substantial rationale for studying the activity of CPG-ODNs in human tumor systems. In this regard, in vitro data indicate that CPG-ODNs can potently activate CTCL patient DCs, leading to IFN- $\alpha$ production, increased expression of critical immune accessory molecules, and enhanced cell-mediated cytotoxicity (52). Moreover, Kim and colleagues have shown in a phase II clinical trial for refractory advanced CTCL that CPG-ODNs administered subcutaneously as a single agent demonstrate therapeutic efficacy, in some cases 
inducing complete clinical responses (97). Therefore, application of CpG-ODNs in a multimodality therapeutic approach that uses photopheresis might also yield significant therapeutic benefit. It is noteworthy that antiviral vaccination strategies that incorporate the use of CpG-ODNs along with viral antigen appear to be markedly superior to those that use antigen alone (98). Since ECP represents an immunization procedure using apoptotic tumor cells, such findings support the use of CPG-ODNs at the time of reinfusion of the treated tumor cells in an effort to directly target the tumor antigens to DCs for processing.

Other mechanisms for activating the DCs of patients with MF/SS that are under preclinical investigation include strategies for the engagement of CD40. As stressed above, there is substantial evidence that a defect in CD40-ligand expression by malignant $\mathrm{T}$ cells plays some role in the depressed production of DC-dependent cytokines (48). Furthermore, coculture of peripheral blood cells of SS patients with hexameric recombinant CD40 ligand resulted in substantial production of IL-12. Clinical trials using this approach have yet to be undertaken. Another strategy that also awaits clinical testing involves the use of an activating anti-CD40 antibody. Animal model studies that have used this approach indicate that enhanced generation of tumor-specific T cells can occur $(99,100)$.

IL-12 is a cytokine known to enhance cytolytic T cell and NK cell activities and to induce IFN- $\gamma$ release and thus has the potential to enhance the antitumor immune response of MF/SS patients. In a small phase I study followed by a limited phase II study, the subcutaneous administration of recombinant IL-12 to a total of 32 patients with MF resulted in a response rate of approximately $50 \%(101,102)$. Since malignant T cells lack the IL-12 $\beta 2$ receptor (103) and are thus incapable of signaling in response to IL-12, it is presumed that the clinical response was not due to the direct effects of the cytokine on the malignant cells. Indeed, serial biopsies of cutaneous plaques during treatment revealed dense infiltrates of $\mathrm{CD} 8^{+} \mathrm{T}$ cells that appeared near the time of initial signs of lesional regression (101). Thus, it is believed that $\mathrm{CD}^{+} \mathrm{T}$ cells with augmented cytolytic activity are the predominant "workhorses" activated in response to IL-12. Whether IL-12 administration has advantages over IFN- $\gamma$ use is presently unknown, but it is hoped that in the future, IL-12 will also find its place in a multimodality therapeutic approach.

\section{Future therapeutic directions for enhancing the host immune response}

Tumor vaccines. A number of different vaccination strategies are being applied to patients with MF/SS, most of which make use of the clonotypic TCR as a source of tumor-specific antigen. Immunogenic epitopes have been identified within both the variable $(\mathrm{V})$ and the constant (C) regions of the clonotypic TCR- $\alpha$ and TCR- $\beta$ receptors $(104,105)$. In some experiments, immunogenic peptides have been directly isolated from the MHC class I molecules on the surface of the malignant clone (104). This confirms that the antigen-processing pathway for endogenous proteins remains intact in the malignant clone and that the clonotypic TCR is subjected to antigen processing and presentation by MHC class I. Consequently, the TCR peptide-MHC complex on the surface of a malignant cell can serve as a target for recognition by $\mathrm{CD}^{+}$CTLs. This has been demonstrated in both healthy donors and patients with MF/SS, in whom immunogenic peptides derived from the clonotypic TCR-induced tumor-specific $\mathrm{CD}^{+} \mathrm{T}$ cells, which were capable of secreting TNF- $\alpha$ (104) as well as lysing autologous tumor cells in vitro (105).
DC-based vaccines are also being investigated for treatment of CTCL (106). Sources of antigen used to pulse DCs prior to vaccination may include tumor-cell lysates, peptides, mimotopes, tumorderived DNA or RNA, and even tumor cell-DC fusions. Maier et al. recently reported on 10 CTCL patients treated with weekly intranodal injections of autologous DCs pulsed with tumor lysate (107). In this study, $50 \%$ of patients had a clinical response to the vaccine, accompanied by an infiltration of $\mathrm{CD}^{+}$cytotoxic cells at the site of regressing lesions as well as molecular remission in some cases. It should be mentioned that clinical responses in this study were associated with a low tumor burden, which underscores the importance of instituting immunotherapy early in the course of the disease (i.e., prior to the development of significant immune dysregulation) (107).

As with any vaccination scheme, the addition of an immune adjuvant(s) may be used in an attempt to enhance the efficacy of the vaccine. Cytokines such as IL-12 (101, 102), IL-15 (52, 108), IL-18 (109), and IL-21 (110) may serve to augment the development, the effectiveness, and/or the maintenance of antitumor CTL responses. Moreover, these same cytokines have also been shown to enhance NK cell activity, which may play an important role in controlling tumor growth in vivo. GM-CSF is another cytokine that has been used as a cancer vaccine adjuvant to enhance both the number and function of DCs $(111,112)$. As discussed earlier, other immuneactivating agents, including TLR agonists (e.g., imidizoquinolines, CPG-ODNs), anti-CD40, and anti-CTLA-4, could be used in conjunction with a tumor vaccine for patients with CTCL.

Other strategies. Monoclonal antibodies and fusion toxins directed against a variety of cell-surface markers have been tested in patients with SS/MF. In addition to denileukin diftitox, described earlier, examples of such antibodies include anti-CD4 and anti-CD52 (known as CamPath) $(113,114)$. These 2 agents have direct potent antitumor activity yet probably induce immunosuppression as well.

CCR4 may represent another possible target for antibody-based therapy for CTCL by virtue of the fact that its expression is relatively specific for skin-homing $\mathrm{T}$ cells, including the malignant cells in both CTCL and ATLL $(18,115)$. Preclinical studies have shown that a monoclonal antibody to CCR4 induces potent antibody-mediated cellular cytotoxicity against malignant $\mathrm{T}$ cell clones $(116,117)$. In addition to lysing CCR $4^{+} \mathrm{T}$ cells in vitro, this antibody reduced the expression of Foxp3 mRNA, suggesting a possible role in depleting Tregs (116).

Histone deacetylase (HDAC) inhibitors represent a novel class of compounds that modulate gene expression by shifting the balance toward acetylation of nucleosomal histones (118). Compounds such as suberoylanilide hydroxamic acid $(118,119)$ and depsipeptide $(120,121)$ have been shown to induce differentiation and/or apoptosis of malignant lymphocytes. In addition, recent data indicate that HDAC inhibitors may upregulate the expression of the IL-2 receptor on malignant T cells, resulting in enhanced susceptibility to killing by denileukin diftitox $(121,122)$.

Finally, bone marrow transplant offers hope to patients with advanced MF/SS that proves refractory to other therapeutic approaches. Allogeneic stem cells from an HLA-identical sibling $(123,124)$ or a matched unrelated donor $(125)$ have induced complete and durable remissions in some patients, characterized by the disappearance of the malignant clone from the peripheral blood (as determined by gene rearrangement studies, flow cytometry, and the lack of circulating Sézary cells). Even in those patients who do not achieve complete remission, a reduc- 
tion in disease severity may be observed (123), which is likely attributable to a graft-versus-MF antitumor effect. The obvious advantages to the use of allogeneic bone marrow transplant include its ability to aggressively deplete the malignant cells from the patient, to reconstitute the immune system, and to induce a graft-versus-tumor response.

Conclusions. A greater understanding of $\mathrm{T}$ cell function and the immunobiology of MF/SS has led to expansion of our therapeutic armamentarium against these diseases. Recent gene expression studies suggest that in the future we may be able to identify subsets of patients who would benefit most from initiation of immunomodulatory therapy earlier in the course of the disease (43). Future challenges include the development of well-designed clinical trials to elucidate the optimal combination and timing of these therapies in our patients. Looking back at the past 30 years, it is remarkable to survey the progress in the approach to treatment of MF/SS, from the past paradigm of cytotoxic chemotherapy to the current focus on targeted therapy that activates host immunity.

\section{Acknowledgments}

The authors thank John R. Stanley for reviewing the manuscript and Sam Dulay for his valuable assistance with the figures.

Address correspondence to: Ellen J. Kim, 2 Maloney Building, 2M31, Department of Dermatology, University of Pennsylvania Health System, 3600 Spruce Street, Philadelphia, Pennsylvania 19104, USA. Phone: (215) 349-5060; Fax: (215) 615-0047; E-mail: Ellen.kim@uphs.upenn.edu.
1. Girardi, M., Heald, P.W., and Wilson, L.D. 2004. The pathogenesis of mycosis fungoides. N. Engl. J. Med. 350:1978-1988.

2. Kazakov, D.V., Burg, G., and Kempf, W. 2004. Clinicopathological spectrum of mycosis fungoides. J. Eur. Acad. Dermatol. Venereol. 18:397-415.

3. Willemze, R., et al. 2005. WHO-EORTC classification for cutaneous lymphomas. Blood. doi:10.1182/ blood-2004-09-3502.

4. Leboit, P.E., and McCalmont, T.H. 1997. Cutaneous lymphomas and leukemias. In Lever's histopathology of the skin. D. Elder, C. Jaworsky, and B. Johnson, editors. Lippincott-Raven. Philadelphia, Pennsylvania, USA. 820 pp

5. Kim, Y.H., et al. 2003. Long-term outcome of 525 patients with mycosis fungoides and Sezary syndrome: clinical prognostic factors and risk for disease progression. Arch. Dermatol. 139:857-866.

6. Weinstock, M.A., and Gardstein, B. 1999. Twentyyear trends in the reported incidence of mycosis fungoides and associated mortality. Am. J. Public Health. 89:1240-1244.

7. Chuang, T.Y., Su, W.P., and Muller, S.A. 1990. Incidence of cutaneous $\mathrm{T}$ cell lymphoma and other rare skin cancers in a defined population. J. Am. Acad. Dermatol. 23:254-256.

8. Fisher, S.G., and Fisher, R.I. 2004. The epidemiology of non-Hodgkin's lymphoma. Oncogene. 23:6524-6534.

9. Bernengo, M.G., et al. 2001. The relevance of the CD4+ CD26- subset in the identification of circulating Sezary cells. Br. J. Dermatol. 144:125-135.

10. Wood, G.S., et al. 1990. Leu-8/CD7 antigen expression by CD3+ T cells: comparative analysis of skin and blood in mycosis fungoides/Sezary syndrome relative to normal blood values. J. Am. Acad. Dermatol. 22:602-607.

11. Vonderheid, E.C., and Bernengo, M.G. 2003. The Sezary syndrome: hematologic criteria. Hematol. Oncol. Clin. North Am. 17:1367-1389.

12. Kim, Y.H., et al. 1996. Clinical stage IA (limited patch and plaque) mycosis fungoides. A long-term outcome analysis. Arch. Dermatol. 132:1309-1313.

13. Diamandidou, E., Cohen, P.R., and Kurzrock, R. 1996. Mycosis fungoides and Sezary syndrome. Blood. 88:2385-2409.

14. Lessin, S.R., Vowels, B.R., and Rook, A.H. 1994 Retroviruses and cutaneous T-cell lymphoma. Dermatol. Clin. 12:243-253.

15. Kupper, T.S., and Fuhlbrigge, R.C. 2004. Immune surveillance in the skin: mechanisms and clinical consequences. Nat. Rev. Immunol. 4:211-222.

16. Hudak, S., et al. 2002. Immune surveillance and effector functions of CCR10(+) skin homing T cells. J. Immunol. 169:1189-1196.

17. Kakinuma, T., et al. 2003. Thymus and activationregulated chemokine (TARC/CCL17) in mycosis fungoides: serum TARC levels reflect the disease activity of mycosis fungoides. J. Am. Acad. Dermatol.
48:23-30.

18. Ferenczi, K., et al. 2002. Increased CCR4 expression in cutaneous T cell lymphoma. J. Invest. Dermatol. 119:1405-1410.

19. Lu, D., et al. 2001. The T-cell chemokine receptor CXCR3 is expressed highly in low-grade mycosis fungoides. Am. J. Clin. Pathol. 115:413-421.

20. Kallinich, T., et al. 2003. Chemokine receptor expression on neoplastic and reactive $\mathrm{T}$ cells in the skin at different stages of mycosis fungoides. J. Invest. Dermatol. 121:1045-1052.

21. Edelson, R.L. 2001. Cutaneous T cell lymphoma: the helping hand of dendritic cells. Ann. N. Y. Acad. Sci. 941:1-11.

22. Berger, C.L., et al. 2002. The growth of cutaneous T-cell lymphoma is stimulated by immature dendritic cells. Blood. 99:2929-2939.

23. Zhang, Q., et al. 1996. Activation of Jak/STAT proteins involved in signal transduction pathway mediated by receptor for interleukin 2 in malignant $\mathrm{T}$ lymphocytes derived from cutaneous anaplastic large T-cell lymphoma and Sezary syndrome. Proc. Natl. Acad. Sci. U. S. A. 93:9148-9153.

24. Wasik, M.A., et al. 1996. Increased serum concentration of the soluble interleukin-2 receptor in cutaneous T-cell lymphoma. Clinical and prognostic implications. Arch. Dermatol. 132:42-47.

25. Vowels, B.R., et al. 1992. Aberrant cytokine production by Sezary syndrome patients: cytokine secretion pattern resembles murine Th2 cells. J. Invest. Dermatol. 99:90-94.

26. Mao, X., et al. 2002. Molecular cytogenetic analysis of cutaneous T-cell lymphomas: identification of common genetic alterations in Sezary syndrome and mycosis fungoides. Br. J. Dermatol. 147:464-475.

27. Sommer, V.H., et al. 2004. In vivo activation of STAT3 in cutaneous T-cell lymphoma. Evidence for an antiapoptotic function of STAT3. Lenkemia. 18:1288-1295.

28. Dereure, O., et al. 2002. Infrequent Fas mutations but no Bax or p53 mutations in early mycosis fungoides: a possible mechanism for the accumulation of malignant $\mathrm{T}$ lymphocytes in the skin. J. Invest. Dermatol. 118:949-956.

29. Whittaker, S. 2001. Molecular genetics of cutaneous lymphomas. Ann. N. Y. Acad. Sci. 941:39-45.

30. McGregor, J.M., et al. 1999. Spectrum of p53 gene mutations suggests a possible role for ultraviolet radiation in the pathogenesis of advanced cutaneous lymphomas. J. Invest. Dermatol. 112:317-321.

31. Scarisbrick, J.J., et al. 2003. Microsatellite instability is associated with hypermethylation of the hMLH1 gene and reduced gene expression in mycosis fungoides. J. Invest. Dermatol. 121:894-901.

32. Navas, I.C., et al. 2002. p16(INK4a) is selectively silenced in the tumoral progression of mycosis fungoides. Lab. Invest. 82:123-132.

33. Wood, G.S., et al. 1994. Detection of clonal T-cell receptor gamma gene rearrangements in early mycosis fungoides/Sezary syndrome by polymerase chain reaction and denaturing gradient gel electrophoresis (PCR/DGGE). J. Invest. Dermatol. 103:34-41.

34. Muche, J.M., et al. 2003. Peripheral blood T-cell clonality in mycosis fungoides and nonlymphoma controls. Diagn. Mol. Pathol. 12:142-150.

35. Dereure, O., et al. 2003. Improved sensitivity of T-cell clonality detection in mycosis fungoides by hand microdissection and heteroduplex analysis. Arch. Dermatol. 139:1571-1575.

36. Yazdi, A.S., et al. 2003. Improved detection of clonality in cutaneous T-cell lymphomas using laser capture microdissection. J. Cutan. Pathol. 30:486-491.

37. Delfau-Larue, M.H., et al. 1998. Prognostic significance of a polymerase chain reaction-detectable dominant T-lymphocyte clone in cutaneous lesions of patients with mycosis fungoides. Blood. 92:3376-3380.

38. Schwab, C., et al. 2002. The use of anti-T-cell receptor-Vbeta antibodies for the estimation of treatment success and phenotypic characterization of clonal T-cell populations in cutaneous T-cell lymphomas. Br. J. Haematol. 118:1019-1026.

39. Vonderheid, E.C., et al. 2002. Update on erythrodermic cutaneous T-cell lymphoma: report of the International Society for Cutaneous Lymphomas. J. Am. Acad. Dermatol. 46:95-106.

40. Yawalkar, N., et al. 2003. Profound loss of T-cell receptor repertoire complexity in cutaneous $\mathrm{T}$-cell lymphoma. Blood. 102:4059-4066.

41. Vowels, B.R., et al. 1994. Th2 cytokine mRNA expression in skin in cutaneous T-cell lymphoma. J. Invest. Dermatol. 103:669-673.

42. Asadullah, K., et al. 1996. Progression of mycosis fungoides is associated with increasing cutaneous expression of interleukin-10 mRNA. J. Invest. Dermatol. 107:833-837.

43. Kari, L., et al. 2003. Classification and prediction of survival in patients with the leukemic phase of cutaneous T cell lymphoma. J. Exp. Med. 197:1477-1488.

44. Hoppe, R.T., et al. 1995. CD8-positive tumorinfiltrating lymphocytes influence the long-term survival of patients with mycosis fungoides. J. Am. Acad. Dermatol. 32:448-453.

45. Zackheim, H.S., et al. 2002. Psoriasiform mycosis fungoides with fatal outcome after treatment with cyclosporine. J. Am. Acad. Dermatol. 47:155-157.

46. Wysocka, M., et al. 2002. Sezary syndrome patients demonstrate a defect in dendritic cell populations: effects of CD40 ligand and treatment with GM-CSF on dendritic cell numbers and the production of cytokines. Blood. 100:3287-3294.

47. De Smedt, T., et al. 1997. Effect of interleukin-10 on dendritic cell maturation and function. Eur. J. Immunol. 27:1229-1235. 
48. French, L.E., et al. 2005. Impaired CD40L signaling is a cause of defective IL-12 and TNF-\{alpha\} production in Sezary syndrome: circumvention by hexameric soluble CD40L. Blood. 105:219-225.

49. Berger, C.L., et al. 2004. Cutaneous T cell lymphoma, malignant proliferation of T-regulatory cells. Blood. 105:1640-1647.

50. Karube, K., et al. 2004. Expression of FoxP3, a key molecule in $\mathrm{CD} 4 \mathrm{CD} 25$ regulatory $\mathrm{T}$ cells, in adult T-cell leukaemia/lymphoma cells. Br. J. Haematol. 126:81-84

51. Yoo, E.K., et al. 2001. Complete molecular remission during biologic response modifier therapy for Sezary syndrome is associated with enhanced helper T type 1 cytokine production and natural killer cell activity. J. Am. Acad. Dermatol. 45:208-216.

52. Wysocka, M., et al. 2004. Enhancement of the host immune responses in cutaneous T-cell lymphoma by $\mathrm{CPG}$ oligodeoxynucleotides and IL-15. Blood. 104:4142-4149.

53. Axelrod, P.I., Lorber, B., and Vonderheid, E.C. 1992. Infections complicating mycosis fungoides and Sezary syndrome. JAMA. 267:1354-1358.

54. Goldgeier, M.H., et al. 1981. An unusual and fatal case of disseminated cutaneous herpes simplex. Infection in a patient with cutaneous $\mathrm{T}$ cell lymphoma (mycosis fungoides). J. Am. Acad. Dermatol. 4:176-180.

55. Evans, A.V., et al. 2004. Cutaneous malignant melanoma in association with mycosis fungoides. J. Am. Acad. Dermatol. 50:701-705.

56. Pielop, J.A., Brownell, I., and Duvic, M. 2003. Mycosis fungoides associated with malignant melanoma and dysplastic nevus syndrome. Int. J. Dermatol. 42:116-122.

57. Molin, L., Thomsen, K., and Volden, G. 1978. Serum $\mathrm{IgE}$ in mycosis fungoides. Br. Med. J. 1:920-921.

58. Tancrede-Bohin, E., et al. 2004. Prognostic value of blood eosinophilia in primary cutaneous T-cell lymphomas. Arch. Dermatol. 140:1057-1061.

59. Suchin, K.R., et al. 2001. Increased interleukin 5 production in eosinophilic Sezary syndrome: regulation by interferon alfa and interleukin 12. J. Am. Acad. Dermatol. 44:28-32.

60. Kim, Y.H., et al. 2003. Topical nitrogen mustard in the management of mycosis fungoides: update of the Stanford experience. Arch. Dermatol. 139:165-173.

61. Zackheim, H.S. 2003. Topical carmustine (BCNU) in the treatment of mycosis fungoides. Dermatol. Ther. 16:299-302.

62. Zhang, C., and Duvic, M. 2003. Retinoids: therapeutic applications and mechanisms of action in cutaneous T-cell lymphoma. Dermatol. Ther. 16:322-330.

63. Herrmann, J.J., et al. 1995. Treatment of mycosis fungoides with photochemotherapy (PUVA): longterm follow-up. J. Am. Acad. Dermatol. 33:234-242.

64. Jones, G., Wilson, L.D., and Fox-Goguen, L. 2003. Total skin electron beam radiotherapy for patients who have mycosis fungoides. Hematol. Oncol. Clin. North Am. 17:1421-1434.

65. McGinnis, K.S., et al. 2003. Psoralen plus long-wave UV-A (PUVA) and bexarotene therapy: an effective and synergistic combined adjunct to therapy for patients with advanced cutaneous T-cell lymphoma. Arch. Dermatol. 139:771-775.

66. McGinnis, K.S., et al. 2004. Low-dose oral bexarotene in combination with low-dose interferon alfa in the treatment of cutaneous T-cell lymphoma: clinical synergism and possible immunologic mechanisms. J. Am. Acad. Dermatol. 50:375-379.

67. Singh, F., and Lebwohl, M.G. 2004. Cutaneous T-cell lymphoma treatment using bexarotene and PUVA: a case series. J. Am. Acad. Dermatol. 51:570-573.

68. Kuzel, T.M., et al. 1995. Effectiveness of interferon alfa-2a combined with phototherapy for mycosis fungoides and the Sezary syndrome. J. Clin. Oncol. 13:257-263.

69. Olsen, E.A., and Bunn, P.A. 1995. Interferon in the treatment of cutaneous T-cell lymphoma. Hematol. Oncol. Clin. North Am. 9:1089-1107.

70. Chiarion-Sileni, V., et al. 2002. Phase II trial of interferon-alpha-2a plus psolaren with ultraviolet light A in patients with cutaneous T-cell lymphoma. Cancer. 95:569-575.

71. Knobler, R.M., et al. 1991. Treatment of cutaneous $\mathrm{T}$ cell lymphoma with a combination of lowdose interferon alfa-2b and retinoids. J. Am. Acad. Dermatol. 24:247-252.

72. Zhang, C., et al. 2002. Induction of apoptosis by bexarotene in cutaneous T-cell lymphoma cells: relevance to mechanism of therapeutic action. Clin. Cancer Res. 8:1234-1240.

73. Budgin, J.B., et al. 2005. Biological effects of bexarotene in cutaneous T-cell lymphoma. Arch. Dermatol. 141:315-321.

74. Duvic, M., et al. 2001. Bexarotene is effective and safe for treatment of refractory advanced-stage cutaneous T-cell lymphoma: multinational phase II-III trial results. J. Clin. Oncol. 19:2456-2471.

75. Fox, F.E., et al. 1999. Retinoids synergize with interleukin-2 to augment IFN-gamma and interleukin-12 production by human peripheral blood mononuclear cells. J. Interferon Cytokine Res. 19:407-415.

76. Richardson, S.K., et al. 2003. Extracorporeal photopheresis and multimodality immunomodulatory therapy in the treatment of cutaneous T-cell lymphoma. J. Cutan. Med. Surg. 7(Suppl. 2):8-12.

77. Suchin, K.R., et al. 2002. Treatment of cutaneous Tcell lymphoma with combined immunomodulatory therapy: a 14-year experience at a single institution. Arch. Dermatol. 138:1054-1060.

78. Yoo, E.K., et al. 1996. Apoptosis induction of ultraviolet light $A$ and photochemotherapy in cutaneous T-cell lymphoma: relevance to mechanism of therapeutic action. J. Invest. Dermatol. 107:235-242.

79. Heald, P.W., and Edelson, R.L. 1988. Photopheresis for T cell mediated diseases. Adv. Dermatol. 3:25-40.

80. Girardi, M., et al. 2002. Transimmunization and the evolution of extracorporeal photochemotherapy. Transfus Apheresis Sci. 26:181-190.

81. Kim, S., Elkon, K.B., and Ma, X. 2004. Transcriptional suppression of interleukin-12 gene expression following phagocytosis of apoptotic cells. Immunity. 21:643-653.

82. Shapiro, M., et al. 2002. Novel multimodality biologic response modifier therapy, including bexarotene and long-wave ultraviolet $\mathrm{A}$ for a patient with refractory stage IVa cutaneous T-cell lymphoma. J. Am. Acad. Dermatol. 47:956-961.

83. Dummer, R., et al. 2004. Adenovirus-mediated intralesional interferon-gamma gene transfer induces tumor regressions in cutaneous lymphomas. Blood. 104:1631-1638.

84. vanderSpek, J.C., et al. 1993. Structure/function analysis of the transmembrane domain of DAB389. interleukin-2, an interleukin-2 receptor-targeted fusion toxin. The amphipathic helical region of the transmembrane domain is essential for the efficient delivery of the catalytic domain to the cytosol of target cells. J. Biol. Chem. 268:12077-12082.

85. Olsen, E., et al. 2001. Pivotal phase III trial of two dose levels of denileukin diftitox for the treatment of cutaneous T-cell lymphoma. J. Clin. Oncol. 19:376-388.

86. Camacho, L.H., et al. 2004. Phase 1 clinical trial of anti-CTLA4 human monoclonal antibody CP675,206 in patients with advanced solid malignancies [abstract]. J. Clin. Oncol. 22(Suppl.):2505.

87. Wu, J.J., Huang, D.B., and Tyring, S.K. 2004. Resiquimod: a new immune response modifier with potential as a vaccine adjuvant for Th1 immune responses. Antiviral Res. 64:79-83.

88. Dockrell, D.H., and Kinghorn, G.R. 2001. Imiqui- mod and resiquimod as novel immunomodulators. J. Antimicrob. Chemother. 48:751-755.

89. Suchin, K.R., Junkins-Hopkins, J.M., and Rook, A.H. 2002. Treatment of stage IA cutaneous T-cell lymphoma with topical application of the immune response modifier imiquimod. Arch. Dermatol. 138:1137-1139.

90. Dummer, R., et al. 2003. Imiquimod induces complete clearance of a PUVA-resistant plaque in mycosis fungoides. Dermatology. 207:116-118.

91. Hurwitz, D.J., Pincus, L., and Kupper, T.S. 2003. Imiquimod: a topically applied link between innate and acquired immunity. Arch. Dermatol. 139:1347-1350.

92. Kawai, T., et al. 2004. Interferon-alpha induction through Toll-like receptors involves a direct interaction of IRF7 with MyD88 and TRAF6. Nat. Immunol. 5:1061-1068.

93. Schon, M.P., and Schon, M. 2004. Immune modulation and apoptosis induction: two sides of the antitumoral activity of imiquimod. Apoptosis. 9:291-298.

94. Jones, T. 2003. Resiquimod 3M. Curr. Opin. Investig. Drugs. 4:214-218.

95. Krieg, A.M. 2003. CpG motifs: the active ingredient in bacterial extracts? Nat. Med. 9:831-835.

96. Lonsdorf, A.S., et al. 2003. Intratumor CpG-oligodeoxynucleotide injection induces protective antitumor T cell immunity. J. Immunol. 171:3941-3946.

97. Kim, Y., et al. 2004. TLR9 agonist immunomodulator treatment of cutaneous T-cell lymphoma (CTCL) with CPG7909 [abstract]. American Society of Hematology Meeting. December 4-7, 2004. San Diego, California, USA. http://www.abstracts2view. com/hem_sandiego2004/.

98. Tritel, M., et al. 2003. Prime-boost vaccination with HIV-1 Gag protein and cytosine phosphate guanosine oligodeoxynucleotide, followed by adenovirus, induces sustained and robust humoral and cellular immune responses. J. Immunol. 171:2538-2547.

99. Bergstrom, R.T., et al. 2004. CD40 monoclonal antibody activation of antigen-presenting cells improves therapeutic efficacy of tumor-specific $\mathrm{T}$ cells. Otolaryngol. Head Neck Surg. 130:94-103.

100. Watanabe, S., et al. 2003. The duration of signaling through CD40 directs biological ability of dendritic cells to induce antitumor immunity. J. Immunol. 171:5828-5836.

101.Rook, A.H., et al. 1999. Interleukin-12 therapy of cutaneous T-cell lymphoma induces lesion regression and cytotoxic T-cell responses. Blood. 94:902-908.

102.Rook, A.H., et al. 1996. The potential therapeutic role of interleukin-12 in cutaneous T-cell lymphoma. Ann. N. Y. Acad. Sci. 795:310-318.

103.Zaki, M.H., et al. 2001. Dysregulation of lymphocyte interleukin-12 receptor expression in Sezary syndrome. J. Invest. Dermatol. 117:119-127.

104.Berger, C.L., et al. 1998. Tumor-specific peptides in cutaneous T-cell lymphoma: association with class I major histocompatibility complex and possible derivation from the clonotypic T-cell receptor. Int. J. Cancer. 76:304-311.

105. Winter, D., et al. 2003. Definition of TCR epitopes for CTL-mediated attack of cutaneous T cell lymphoma. J. Immunol. 171:2714-2724.

106. Muche, J.M., and Sterry, W. 2002. Vaccination therapy for cutaneous T-cell lymphoma. Clin. Exp. Dermatol. 27:602-607.

107. Maier, T., et al. 2003. Vaccination of patients with cutaneous T-cell lymphoma using intranodal injection of autologous tumor-lysate-pulsed dendritic cells. Blood. 102:2338-2344.

108. Berard, M., et al. 2003. IL-15 promotes the survival of naive and memory phenotype CD8+ T cells. J. Immunol. 170:5018-5026.

109.Son, Y.I., et al. 2001. Interleukin-18 (IL-18) synergizes with IL-2 to enhance cytotoxicity, interferon- 
gamma production, and expansion of natural killer cells. Cancer Res. 61:884-888.

110. Strengell, M., et al. 2003. IL-21 in synergy with IL-15 or IL-18 enhances IFN-gamma production in human NK and T cells. J. Immunol. 170:5464-5469.

111.Miller, G., et al. 2002. Endogenous granulocyte-macrophage colony-stimulating factor overexpression in vivo results in the long-term recruitment of a distinct dendritic cell population with enhanced immunostimulatory function. J. Immunol. 169:2875-2885.

112.Chang, D.Z., et al. 2004. Granulocyte-macrophage colony stimulating factor: an adjuvant for cancer vaccines. Hematology. 9:207-215.

113.Lundin, J., et al. 1998. CAMPATH-1H monoclonal antibody in therapy for previously treated lowgrade non-Hodgkin's lymphomas: a phase II multicenter study. European Study Group of CAMPATH-1H Treatment in Low-Grade Non-Hodgkin's Lymphoma. J. Clin. Oncol. 16:3257-3263.

114.Lundin, J., et al. 2003. Phase 2 study of alemtuzumab (anti-CD52 monoclonal antibody) in patients with advanced mycosis fungoides/Sezary syndrome. Blood. 101:4267-4272.

115.Ishida, T., et al. 2003. Clinical significance of CCR4 expression in adult T-cell leukemia/lymphoma: its close association with skin involvement and unfavorable outcome. Clin. Cancer Res. 9:3625-3634.

116.Ishida, T., et al. 2004. The CC chemokine receptor 4 as a novel specific molecular target for immunotherapy in adult T-cell leukemia/lymphoma. Clin. Cancer Res. 10:7529-7539.

117. Niwa, R., et al. 2004. Defucosylated chimeric antiCC chemokine receptor 4 IgG1 with enhanced antibody-dependent cellular cytotoxicity shows potent therapeutic activity to T-cell leukemia and lymphoma. Cancer Res. 64:2127-2133.

118. Mitsiades, N., et al. 2003. Molecular sequelae of histone deacetylase inhibition in human malignant B cells. Blood. 101:4055-4062.

119.Kelly, W.K., et al. 2003. Phase I clinical trial of histone deacetylase inhibitor: suberoylanilide hydroxamic acid administered intravenously. Clin. Cancer Res. 9:3578-3588.

120.Piekarz, R.L., et al. 2001. Inhibitor of histone deacetylation, depsipeptide (FR901228), in the treatment of peripheral and cutaneous T-cell lymphoma: a case report. Blood. 98:2865-2868.

121.Piekarz, R.L., et al. 2004. T-cell lymphoma as a model for the use of histone deacetylase inhibitors in cancer therapy: impact of depsipeptide on molecular markers, therapeutic targets, and mechanisms of resistance. Blood. 103:4636-4643.

122. Shao, R.H., et al. 2002. Arginine butyrate increases the cytotoxicity of DAB(389)IL-2 in leukemia and lymphoma cells by upregulation of IL-2Rbeta gene. Leuk. Res. 26:1077-1083.

123.Burt, R.K., et al. 2000. Allogeneic hematopoietic stem cell transplantation for advanced mycosis fungoides: evidence of a graft-versus-tumor effect. Bone Marrow Transplant. 25:111-113.

124.Soligo, D., et al. 2003. Treatment of advanced mycosis fungoides by allogeneic stem-cell transplantation with a nonmyeloablative regimen. Bone Marrow Transplant. 31:663-666.

125. Molina, A., et al. 1999. Remission of refractory Sezary syndrome after bone marrow transplantation from a matched unrelated donor. Biol. Blood Marrow Transplant. 5:400-404. 